This file is the 'Submitted version under review' (SMUR, original submission prior to peer review process) of the following published article:

Yeom, S., Choi-Lundberg, D.L., Fluck, A.E., Sale, A. (2017). Factors influencing undergraduate students' acceptance of a haptic interface for learning gross anatomy, Interactive Technology and Smart Education 14(1): 50-66. http://dx.doi.org/10.1108/ITSE$\underline{\text { 02-2016-0006 }}$

The version of record is available at http://www.emeraldinsight.com/loi/itse

This 'Submitted version under review' version may be posted on the institutional repository after publication of the 'version of record' (with journal volume, issue, and page numbers) as per http://www.emeraldgrouppublishing.com/authors/writing/author_rights.htm

The version of record was published on or about 9 April 2017. 


\section{Factors influencing undergraduate students' acceptance of a haptic interface for learning gross anatomy}

Author Details (please list these in the order they should appear in the published article)

Author 1 Name: Soonja Yeom

Department: School of Engineering and ICT

University/Institution: University of Tasmania

Town/City: Hobart

State (US only):

Country: Australia

Author 2 Name: Derek Choi-Lundberg

Department: School of Medicine

University/Institution: University of Tasmania

Town/City: Hobart

State (US only):

Country: Australia

Author 3 Name: Andrew Fluck

Department: School of Education

University/Institution: University of Tasmania

Town/City: Launceston

State (US only):

Country: Australia

Author 4 Name: Arthur Sale

Department: School of Engineering and ICT

University/Institution: University of Tasmania

Town/City: Hobart

State (US only):

Country: Australia

\section{Corresponding author: Soonja Yeom \\ Corresponding Author's Email: s.yeom@utas.edu.au}

\section{Biographical Details:}

Soonja Yeom, is a Lecturer in School of Engineering and ICT. She teaches computer security and programming for the internet. Currently she is a PhD candidate with a thesis titled 'Undergraduate student acceptance of haptic simulation in gross anatomy learning'. Her research interests include technology-enhanced learning, human computer interface, and computer security.

Derek Choi-Lundberg, PhD, is Senior Lecturer in Anatomy, School of Medicine, University of Tasmania. He teaches gross anatomy, neuroanatomy and embryology to first to third year medical students, and coordinates year 1 , semester 2 of the MBBS course. His research interests include medical and anatomical sciences education, technology-enhanced learning, assessment, near-peer and reciprocal peer teaching \& learning, and student learning approaches in anatomy.

Andrew Fluck, $\mathrm{PhD}$, is a Senior Lecturer in Information Technology and teacher educator at the University of Tasmania. He has an interest in curriculum transformation through the use of computers; developed an eExam system for students to use their own computers in high stakes assessment; and serves on the executive of Working Group 3.3 (research into educational applications of information technologies) for IFIP/UNESCO. See more at http://andrew.fluck.id.au/.

Arthur Sale, $\mathrm{PhD}$, is Emeritus Professor of Computer Science at the University of Tasmania. He has lectured on many aspects of ICT over a career of 55 years including human-computer interfaces, served as Chairman of the University's Professorial Board, as Pro Vice-Chancellor and was for 20 years head of the ICT department. He has published over 90 papers, many book chapters and two books. His primary research interests lie in computer design, programming languages, and the effects of the Internet on society. 


\begin{abstract}
:
Purpose - This research evaluates factors influencing undergraduate students' acceptance of a computer-aided learning (CAL) resource using the Phantom Omni haptic stylus to enable rotation, touch and kinaesthetic feedback, and display of names of three-dimensional (3D) human anatomical structures on a visual display. Design/methodology/approach - Software was developed using the software development life cycle, and was tested by students enrolled in various bachelor degrees at three stages of development within Technology Acceptance Model, action research and design research methodology frameworks, using mixed methods of quantitative and qualitative analysis.

Findings - The learning system was generally well-accepted, with usefulness $(72 \pm 18$, mean \pm standard deviation, $0-100$ visual analogue scale) rated higher $(\mathrm{p}<0.001)$ than ease of use $(57 \pm 22)$. Ease of use ratings declined across the three versions as modules were added and complexity increased. Students with prior experience with 3D interfaces had higher intention to use the system, and scored higher on identification of anatomical structures. Students with greater kinaesthetic learning preferences tended to rate the system higher. Haptic feedback was considered the best aspect of the system but students wanted higher spatial resolution and lower response times.

Originality/value - Previous research relating to haptic devices in medical and health sciences has largely focused on advanced trainees learning surgical or procedural skills. The present research suggests that incorporating haptic feedback into virtual anatomical models may provide useful multisensory information in learning anatomy at the undergraduate level.
\end{abstract}

Keywords: Haptic, force-feedback, kinaesthetic learning, VARK learning styles, human anatomy, undergraduate medical students

Article Classification: Research article

\title{
Introduction
}

[The first paragraph of this SMUR version has been deleted, as it has been replaced with a rewritten paragraph in the version of record].

Teaching and learning human gross anatomy may use various resources, including lectures, textbooks, atlases, dissection of human cadavers, prosected wet and plastinated specimens, three-dimensional (3D) printed specimens based on prosections or medical imaging data, plastic anatomical models, living surface anatomy, body painting, radiological images, and multimedia on computers, tablets, and mobile devices (Sugand et al., 2010; Gaglani and Topol, 2014; Rengier et al., 2010; Lim et al., 2015). Dissection combines visual and touch sensation with auditory sensation through discussion amongst teachers and students, and thus engages multiple sensory modalities (Granger, 2004), as do 3D specimens and models. Due to reduced time available for gross anatomy in crowded curricula, medical and other health sciences students typically have only limited opportunities to learn from cadavers, prosected specimens, and/or 3D physical models (Fitzgerald et al., 2008; Drake et al., 2009; Craig et al., 2010; Bouwer et al., 2015). Furthermore, some universities lack access to donated cadavers and dissection facilities, or have eliminated dissection due to cost, ethical, safety, sociocultural or religious concerns, and potential negative effects on students' attitudes towards future patients (McLachlan et al., 2004; Lim et al., 2015). In part as a consequence of the above issues, as well as to take advantage of the potential of technology to enhance learning experiences (Burns, 2013) and to provide greater flexibility in the place and tempo of learning (Johnson et al., 2013), computer-aided learning (CAL) resources for anatomy have been developed.

Many CAL resources for anatomy are based upon multimedia design principles and cognitive load theory, with non-redundant images, text, and auditory information integrated to take advantage of the user's parallel cognitive processing of visual and auditory information 
and multisensory learning mechanisms (Clark and Mayer, 2003; Shams and Seitz, 2008; van Merrienboer and Sweller, 2010; Ayres, 2015). Basic e-book versions of traditional anatomy textbooks and atlases use static 2D images. In contrast, many CAL resources provide fadable, layered 2D images allowing virtual dissection (Saltarelli et al., 2014) and/or rotatable 3D images (with or without stereoscopic viewing) (Cornwall and Pollard, 2012; Lewis et al., 2014b; Temkin et al., 2006; Yammine and Violato, 2015). A meta-analysis of 36 studies found that 3D images are superior to 2D in spatial and factual anatomical knowledge, satisfaction and perceived effectiveness (Yammine and Violato, 2015). Comparing 3D CAL resources with dissection has produced mixed results, either similar performance on spatial anatomical knowledge (Codd and Choudhury, 2011) or worse performance from 3D CAL resources on identification and explanation questions (Saltarelli et al., 2014).

Haptic feedback includes a combination of somatosensory (touch) sensation mediated by tactile receptors in skin, and kinaesthetic sensation, mediated by kinaesthetic receptors in muscles, tendons, and joints (Panait et al., 2009). Physical anatomical models can be explored with sight and touch, and improve spatial anatomical understanding more than textbooks and CAL resources without haptic feedback (Preece et al., 2013). Touch and kinaesthetic sensation through feeling and manipulating real human tissues is available through studying cadavers, prosected specimens, and living human models (McLachlan and Patten, 2006; Dev et al., 2002), and is particularly important for surgical and procedural training (Dev et al., 2002). Thus, adding haptic feedback to CAL resources has been an active area of research and development for two decades, including for surgical training (Hoffman and Vu, 1997; Dev et al., 2002; Panait et al., 2009; Fang et al., 2014; Ruthenbeck and Reynolds, 2015; Basdogan et al., 2004; Esteban et al., 2014; Kim et al., 2013; Schvartzman et al., 2014; Thomas, 2013; Wu et al., 2014), clinical procedural training (Arevalo et al., 2013), palpation training (Howell et al., 2008; Ullrich and Kuhlen, 2012), and anatomical education (Dev et al., 2002; Kinnison et al., 2009; Sakellariou et al., 2009; Ingole et al., 2015; Khot et al., 2013; Lewis et al., 2014a; Weber et al., 2012).

Student acceptance of and learning from CAL resources incorporating haptic feedback have been evaluated in various contexts. For example, performance of complex laparoscopic surgery tasks is improved by provision of haptic feedback compared to no haptic feedback (Panait et al., 2009). Medical residents rated virtual dissection of a temporal bone simulator using a Phantom Omni haptic device similar to plastic models, but lower than cadaveric temporal bone dissection (Fang et al., 2014). Students trained only on HapTEL virtual teeth performed as well as those trained on traditional manikins with plastic teeth (Arevalo et al., 2013). Most first year veterinary students who used a 'haptic cow' rectal palpation simulator agreed that it was useful for learning the feel and locations of anatomical structures (Kinnison et al., 2009). Post-graduate surgical trainees using a 3D stereoscopic virtual reality system with haptic interface (CyberTouch gloves) improved their knowledge of inguinal canal anatomy more than the traditional 2D resources group, and rated the system higher on engagement, ease of use, and learning spatial relationships (Sakellariou et al., 2009).

This research article describes the evaluation of a CAL resource with a visual display and a Phantom Omni haptic interface for learning human anatomy, designated 'Learning Anatomy with Haptic Feedback System' (LAHFS), within frameworks of the Technology Acceptance Model, action research and design research. A previous study (Yeom et al., 2013) reported preliminary analysis of user acceptance of two versions of the system by students in the Bachelor of Computing (BComp) or Bachelor of Medicine / Bachelor of Surgery (MBBS). The present study included a third version of the system incorporating a formative quiz for rehearsal of knowledge; involved an additional study population of students from several Bachelor courses including health sciences and education enrolled in a second-year anatomy and physiology unit; and analysed factors influencing user acceptance, including increasing 
complexity of the system from versions 1 to 3, gender, course/unit of study, prior experience with haptic or 3D systems, and preferred learning styles. Research questions (RQ) of the present study were the following:

- RQ1: What are undergraduate students' levels of acceptance of LAHFS?

- RQ2: Which user characteristics influence learning from and acceptance of LAHFS?

- RQ3: Which elements of LAHFS influence user acceptance?

\section{Methods}

\section{Research Methodologies}

Action research and design research frameworks, incorporating quantitative survey questions and qualitative thematic analysis were used. Action research includes cycles of planning, acting, observing, and reflecting (Lingard and Kennedy, 2010). Similarly, design research includes cycles of analysis, design, evaluation and revision to develop a solution for a problem in a context (Plomp, 2009). Initial discussions with an anatomy lecturer and a survey of third year medical students explored issues in learning anatomy (Yeom, 2011) and informed development of version 1 of the haptic system. Further development of the haptic system through versions 2 and 3 was informed by feedback from an anatomy lecturer and undergraduate students in various bachelor degrees (courses, majors) or units (subjects) as described below.

\section{Educational context}

This study was conducted at the University of Tasmania, Australia, as approved by the Social Science Human Research Ethics Committee Tasmania Network (reference H0011743), and involved undergraduate students in several courses. The majority of participants were Bachelor of Medicine / Bachelor of Surgery (MBBS) students; gross anatomy teaching in this course has been described previously (Choi-Lundberg et al., 2015, 2016). Additionally, Bachelor of Computing (BComp) students participated in user test 1. Furthermore, students in the second-year unit Anatomy and Physiology 2 (A\&P2), which covers several organ systems including cardiovascular, respiratory, digestive, urinary and reproductive, participated in user test 3. Students in A\&P2 were enrolled in one of several courses including Bachelor of Education (Health and Physical Education and Outdoor Education), Bachelor of Exercise Science, and Bachelor of Human Movement.

\section{User tests}

Recruitment of students and testing environments for user tests 1 and 2 were described previously (Yeom et al., 2013). For user test 3, students in MBBS year 1 (MBBS1) and A\&P2 were invited to participate via an email or learning management system announcement, along with a reminder at the beginning of the practical laboratory class at which the haptic system was set up. The MBBS1 practical was on the basic anatomy of several organ systems, including cardiovascular, respiratory, and digestive. The A\&P2 practical was on the urinary (renal) system; the cardiovascular, respiratory and digestive systems were covered in practicals earlier in the semester.

In each user test, the student was first given the participant information sheet to read and sign. After a brief explanation and demonstration of LAHFS, the participant was invited to try the modules, as described below. Finally, the participant was given the questionnaire (described below). 


\section{Description of haptic system}

The 'Learning Anatomy with Haptic Feedback System' (LAHFS) was built by the first author. The Software Development Life Cycle, particularly the waterfall model, was used for developing and implementing LAHFS, including identifying system and software requirements, preliminary design based on analysis, program design, code and debug, test and pre-operations, operations and maintenance, with iterations between successive steps (Davis et al., 1988; Royce, 1970; Bassil, 2012). LAHFS provides haptic feedback on selected organs and enables the user to rotate and select anatomical structures on a computer screen using the Phantom Omni haptic feedback stylus (Yeom et al., 2013). The system was developed with Visual Studio 2010 in C++ and OpenGL with OpenHaptic API (Itkowitz et al., 2005). 3D images of organs were received from Mark Billinghurst of the HITLab, NZ. The computer system for user test 1 was an Intel ® Core TM Duo CPU @ 2GHz, RAM 2GB, and for user tests 2 and 3 was Intel ${ }^{\circledR}$ Core TM i7-2600 CPU @ 3.4GHz, RAM 16GB. Visual data was updated at $30 \mathrm{~Hz}$ and haptic feedback at $1000 \mathrm{~Hz}$ as suggested by Coles and colleagues (2011). The implementation took account of behavioral rehearsal as an active learning technique and its positively moderated relationship to skills (Edmunds et al., 2013). The system implementation was informed by cognitive load theory (Paas et al. 2003), with simplification of tasks in learning and self-assessment designed to reduce extraneous cognitive load (Young et al., 2014).

Version 1 of LAHFS had one module, consisting only of the liver and lungs, to provide contrasting haptic feedback. Version 2 of LAHFS had two modules, module 1 from version 1 , and module 2 with heart chambers and blood vessels with 21 labelled structures, with labels turned on and off by clicking a button on the haptic device while hovering over a structure (Yeom et al., 2013). Version 3 of LAHFS had three modules, modules 1 and 2 as above with four additional blood vessels labelled in module 2 , and module 3 consisting of a quiz, with 10 questions requiring the user to click on a named structure, randomly and without repetition selected from the 25 structures of module 2. The cardiovascular system was chosen for modules 2 and 3 to enable MBBS students to gain useful learning aligned to the learning objectives of the practical laboratory class at which the user tests were conducted.

\section{Survey instruments}

The questionnaire in all three user tests included several items using a Visual Analogue Scale (VAS) response scale (0 to 100), a few multiple-choice or fill-in-the-blank demographic questions, open-response feedback, and, in user test 3 only, Neil Fleming's VARK (visual, aural, read/write, and kinesthetic) learning style questionnaire version 7.2 (Fleming, 1995; VARK Learn Limited, 2016). Demographic questions included age, gender, course/unit of study, and previous experience using haptic or 3D interfaces. Several VAS questions were based on the Technology Acceptance Model (TAM), which posits that usage of technology is influenced by perceived usefulness and ease of use (Chuttur, 2009; Marangunić and Granić, 2015; Zacharis, 2012). Although several items are usually used to measure each construct of perceived usefulness and ease of use, each has high internal consistency (Legris et al., 2003); therefore, in the present study, single survey items were used for these constructs, an approach supported by other studies (Jonas and Norman, 2011).

Survey questions were rephrased slightly across user tests; user test 3 versions (except as indicated) were as follows:

- Were you performing well with the system?

- Was the system useful for exploring the anatomical region?

- Was it easy to use the system to explore the anatomical region?

- Did you get mentally stressed while using the system? 
- Did you get physically stressed while using the system?

- Would you use this system as an aid to learning when it is fully developed? (user test 2 only)

- Would you recommend the University use a system based on this one? (user test 3 only)

- Was the quiz useful as a check on understanding? (user test 3 only)

The user test 3 questionnaire also asked students to rank the following anatomy learning sessions or resources from $1=$ most useful to $8=$ least useful: lectures/tutorials/practicals (LTP) (in-class learning), LTP notes, software, websites, textbooks (including eBooks), atlases, the LAHFS tactile (haptic) interface system, and other resources. For the LAHFS, students were instructed to consider its potential usefulness in relation to other resources currently used.

Open-response items varied across the three user tests. The first and second user test questionnaires simply invited comments. The third user test survey included specific questions: 'What were the best aspects of the system?', 'What aspects of the system were most in need of improvements? What suggestions do you have for improvement?' and 'What other features would you like to see in the system to aid your learning?'

\section{Statistical analysis}

IBM SPSS Statistics version 22 and Microsoft Excel for Mac 2011 and PC were used for quantitative data analysis. Bar graphs with error bars show mean and standard deviation. Data are summarised as mean \pm standard deviation with median in parentheses. Nonparametric statistical tests (Mann-Whitney U and Kruskal-Wallis one-way ANOVA followed by post-hoc Mann-Whitney $U$ ) were used if one or more normality tests (skewness, kurtosis, and Shapiro-Wilk tests) were $\mathrm{p}<0.05$ in two or more groups, or if one group had one or more normality tests $\mathrm{p}<0.025$; otherwise, parametric tests were used ( $t$-tests and one-way Analysis of Variance, ANOVA, with Gabriel's post-hoc for unequal group sizes or Games-Howell post-hoc if the equal variance assumption was violated). Friedman's two-way ANOVA by ranks with Wilcoxon signed ranked tests for pair-wise comparisons were used to compare rankings. To analyse correlations between variables, standard multiple regression or Pearson's $r$ were used.

\section{Qualitative analysis}

Replies to open-response questions were independently coded by two of the authors, and the qualitative methodology of thematic analysis was used to identify themes (Braun and Clarke, 2006).

\section{Results}

\section{Participants in user tests}

Eighty-nine undergraduate students, including 58 males and 31 females, age $21.0 \pm 3.4$ (20) years, participated in user tests $1(n=18), 2(n=27)$, and $3(n=44)$. A total of 59 students enrolled in the MBBS course participated, 8 of 230 (3.5\%) year 2 and 3 students (MBBS2/3) in user test 1, 27 of 115 (23.5\%) year 1 students (MBBS1) in user test 2, and 24 of $120(20 \%)$ MBBS1 (different cohort) in user tests 3. Additionally, 10 of $20(50 \%)$ invited students in the Bachelor of Computing (BComp) course participated in user test 1, and 20 of 64 (31\%) 
students enrolled in the unit Anatomy and Physiology (A\&P2) from a variety of Bachelor courses participated in user test 3 .

\section{User acceptance of the haptic system}

Across all three versions of the system, users gave generally high ratings (on a 100 point scale) to usefulness of the system $72 \pm 18$ (76), their performance with the system $60 \pm 24$ (66), and ease of use $57 \pm 22$ (60). Usefulness was rated higher than ease of use ( $\mathrm{p}<0.001)$. Ratings of mental stress $28 \pm 25$ (21) and physical stress $22 \pm 24$ (14) were low. Ratings of performance, usefulness, and ease of use strongly positively correlated with each other, but correlated weakly to moderately negatively with mental and physical stress. The two stress measures strongly positively correlated with each other (Table 1).

[Table 1]

Table 1. Correlations (Pearson's r) between VAS questions across versions 1, 2, and 3. ${ }^{a} \mathrm{p} \leq 0.001,{ }^{b} \mathrm{p} \leq 0.01$

\begin{tabular}{|l|l|l|l|l|}
\hline & System useful & $\begin{array}{l}\text { System easy to } \\
\text { use }\end{array}$ & $\begin{array}{l}\text { Mentally } \\
\text { stressful }\end{array}$ & $\begin{array}{l}\text { Physically } \\
\text { stressful }\end{array}$ \\
\hline Performed well & $0.473^{a}$ & $0.596^{a}$ & $-0.360^{a}$ & $-0.291^{b}$ \\
\hline System useful & & $0.541^{a}$ & -0.147 & -0.130 \\
\hline $\begin{array}{l}\text { System easy to } \\
\text { use }\end{array}$ & & & $-0.293^{b}$ & -0.208 \\
\hline $\begin{array}{l}\text { Mentally } \\
\text { stressful }\end{array}$ & & & & $0.648^{a}$ \\
\hline
\end{tabular}

\section{Intention to use the system}

Users of version 2 indicated that they were likely to use the system when fully developed, $74 \pm 17$ (75); and users of version 3 that they would recommend that the university use a system based on the present version, $59 \pm 21$ (63); neither question was included in user test 1. Although these two questions are different, both are related to intention to use the system. Standard multiple regression of these questions against the five VAS questions above yielded an overall strong positive correlation, $r=0.652$, adjusted $r^{2}=0.374, F=8.296, p<0.001$. Zero-order and part-correlations are shown in Table 2, with 'system useful' significantly positively correlated with 'would use/recommend'.

[Table 2.]

Table 2. Correlations of intention to use the system with other VAS questions.

\begin{tabular}{|l|l|l|l|}
\hline Question & $\begin{array}{l}\text { Zero-order } \\
\text { correlation }\end{array}$ & $\begin{array}{l}\text { Part } \\
\text { correlation }\end{array}$ & p value \\
\hline Performed well & 0.477 & 0.174 & 0.092 \\
\hline System useful & 0.569 & 0.285 & 0.007 \\
\hline System easy to use & 0.517 & 0.181 & 0.079 \\
\hline Mentally stressful & -0.097 & 0.056 & 0.583 \\
\hline Physically stressful & -0.036 & 0.095 & 0.353 \\
\hline
\end{tabular}




\section{Quiz scores and rating of usefulness of quiz}

Version 3 included a quiz to provide participants the opportunity to rehearse their knowledge through identifying anatomical structures. The usefulness of this quiz was rated highly by participants, $77 \pm 18$ (80). Participants generally did well on the quiz, $71 \% \pm 26$ $(80 \%)$. There were moderate positive correlations between quiz score with rating of usefulness of the quiz, $r=0.443(\mathrm{p}=0.003)$, and between quiz score with rating of performance with the system, $r=0.350(\mathrm{p}=0.021)$.

\section{Factors influencing user acceptance: complexity of system}

As described in Methods, LAHFS increased in complexity from version 1 to 3 , particularly from version 1 to 2 . Ratings of performance with the system, usefulness, and ease of use tended to decline from versions 1 to 3 (Figure 1). However, the only statistically significant change was for ease of use (median 70, 60, and 55, respectively; Kruskal-Wallis one-way ANOVA, $\mathrm{H}=12.583, \mathrm{p}=0.002$ ), with significant differences for version 1 vs 2 $(\mathrm{p}=0.026)$ and 1 vs $3(\mathrm{p}<0.001)$, but not 2 vs $3(\mathrm{p}=0.227)$.

[Figure 1.]

Figure 1. Visual analogue scale (VAS) ratings of system versions (v) 1, 2, and 3 . The data from versions 1 and 2 were previously reported in Table 1 of (Yeom et al., 2013). For this paper, the original VAS survey data were reanalysed independently by two authors and the average computed, resulting in slightly different values for some questions to those reported previously (maximum difference $2 \%$ ).

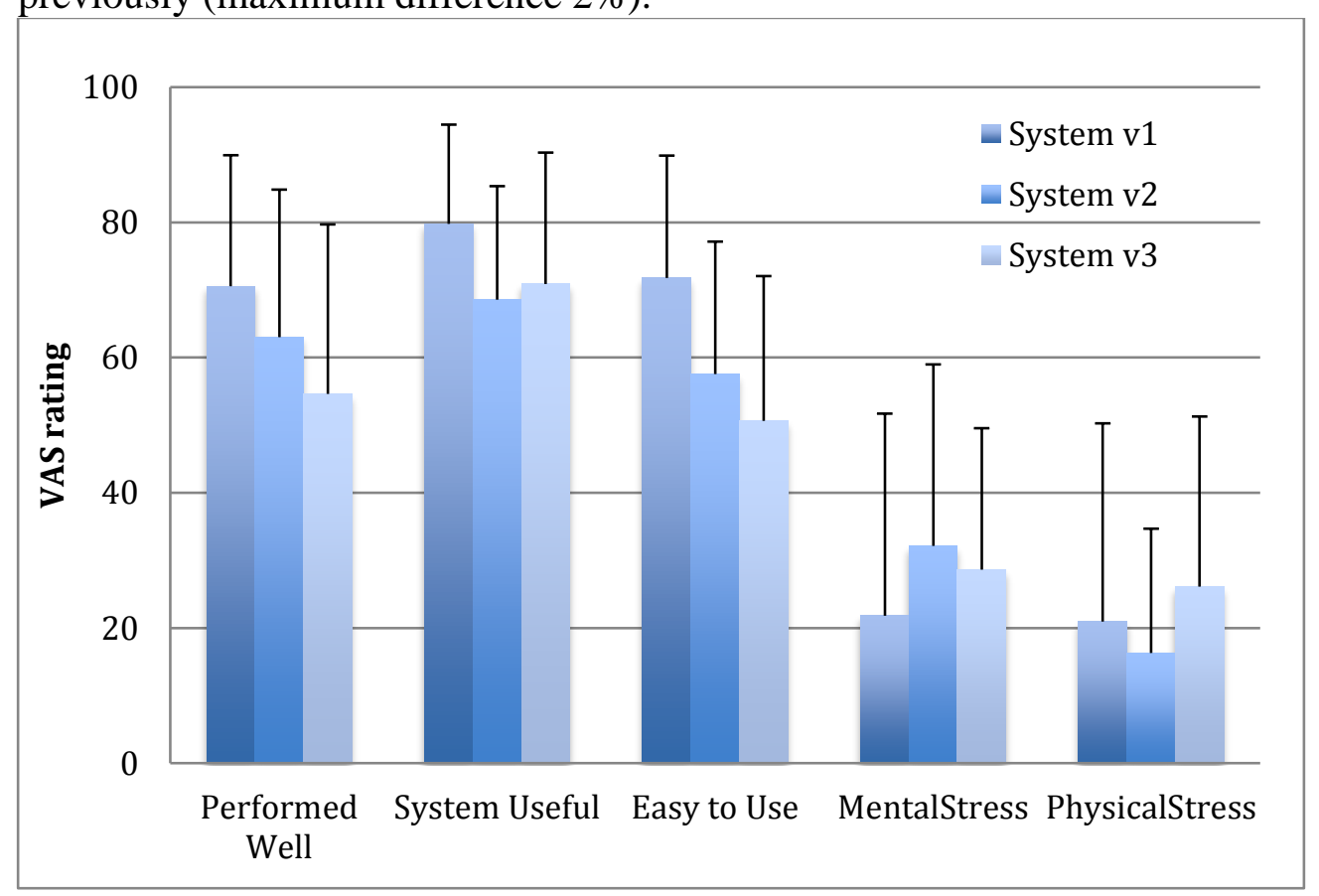

\section{Factors influencing user acceptance: gender}

The only statistically significant difference between genders on VAS questions was 'performed well', with females rating their performance lower than males, $52 \pm 26$ (55) vs $65 \pm 21$ (70), respectively, t-test $\mathrm{p}=0.017$. Despite this, females indicated they were more 
likely to use or recommend the system than males, $68 \pm 16$ (70) vs $61 \pm 24$ (60), t-test $\mathrm{p}=0.037$. Quiz scores of learning achievement did not differ between females $74 \% \pm 28$ $(80 \%)$ and males $69 \% \pm 24(80 \%)$.

\section{Factors influencing user acceptance: course/unit of study}

There were no significant differences between BComp $(n=10)$ and MBBS2/3 $(n=8)$ students' VAS question ratings in User test 1 . User test 2 included only MBBS1 students $(n=25)$, so comparisons by course/unit were not possible within this user test. In user test 3, MBBS1 students ( $n=24$, a different cohort from user test 2) rated the usefulness of the system higher than A\&P2 students from various Bachelor's courses ( $n=20), 76 \pm 20$ (83) vs $64 \pm 17$ (70), respectively, $\mathrm{p}=0.013$; and also rated the usefulness of the quiz higher, $83 \pm 15$ (85) vs $70 \pm 20$ (75), respectively, $\mathrm{p}=0.012$. MBBS students did better on the quiz than A\&P2 students, $78 \% \pm 23(80 \%)$ vs $63 \% \pm 26(65 \%)$, respectively, $\mathrm{p}=0.031$.

\section{Factors influencing user acceptance: prior experience with haptic or 3D systems}

Most students had no prior experience with haptic systems $(n=74)$, while some had used a haptic device on at least one prior occasion $(n=15)$. There were no significant differences on ratings of any of the VAS questions between these two groups, although there was a trend for ease of use to be rated higher by those with prior experience with haptic systems than those without, $65 \pm 22$ (64) vs $55 \pm 21$ (60), respectively, $\mathrm{p}=0.138$.

Students who had prior experience with 3D interfaces $(n=63)$ were more likely than those who had none $(n=26)$ to use or recommend the system, $68 \pm 19$ (70) vs $56 \pm 23$ (56), respectively, $\mathrm{p}=0.025$. There were also trends for higher ratings of performance with the system $64 \pm 23$ (70) vs $53 \pm 25$ (50), p=0.071, and ease of use $59 \pm 21$ (60) vs $52 \pm 23$ (54), $\mathrm{p}=0.180$. Students with prior experience with $3 \mathrm{D}$ interfaces performed better on the quiz than those without, $78 \% \pm 21(80 \%)$ vs $59 \% \pm 30(60 \%)$, respectively, $\mathrm{p}=0.050$.

\section{Factors influencing user acceptance: VARK learning styles}

The VARK questionnaire version 7.2 (VARK Learn Ltd. 2016) was administered to participants in user test 3. The percentage of visual (V), aural (A), read/write (R), and kinaesthetic $(\mathrm{K})$ options chosen out of the total number of responses selected by each participant ( $\mathrm{n}=43$ completed questionnaires) were V 23\% \pm 10 (24\%), A 25\% \pm 12 (24\%), R $22 \% \pm 9(21 \%)$, and $\mathrm{K} 29 \% \pm 13(28 \%)$. These percentages are similar to those reported on the VARK website, based on 147,362 respondents from September to November 2015: V 22.0\%, A 25.6\%, R 23.8\%, and K 28.6\% (VARK Learn Limited, 2016).

Correlations of VARK percentages with the VAS questions are shown in Table 3. Although none of the correlations were statistically significant, kinaesthetic learning preferences weakly positively correlated $(r>0.1)$ with all VAS questions except for system useful. Visual learning preferences weakly positively correlated with system useful and quiz useful, while aural and read/write had negative or near-0 correlations with all VAS questions. Additionally, only kinaesthetic preferences weakly positively correlated with quiz results.

[Table 3.]

Table 3. Correlations (Pearson's r) of VARK learning style percentages with VAS questions and with quiz results. Correlations $r>0.1$ are highlighted in green and $r<-0.1$ in orange. None were statistically significant. 


\begin{tabular}{|l|r|r|r|r|r|r|r|r|}
\hline & $\begin{array}{r}\text { Performed } \\
\text { well }\end{array}$ & $\begin{array}{r}\text { System } \\
\text { useful }\end{array}$ & $\begin{array}{r}\text { Easy to } \\
\text { use }\end{array}$ & $\begin{array}{r}\text { Mentally } \\
\text { stressed }\end{array}$ & $\begin{array}{r}\text { Physically } \\
\text { stressed }\end{array}$ & $\begin{array}{r}\text { Would } \\
\text { Recommend }\end{array}$ & $\begin{array}{r}\text { Quiz } \\
\text { useful }\end{array}$ & $\begin{array}{r}\text { Quiz } \\
\text { result }\end{array}$ \\
\hline V \% & -0.005 & 0.131 & -0.021 & -0.098 & -0.041 & 0.018 & 0.197 & -0.107 \\
\hline A \% & -0.151 & -0.173 & -0.115 & -0.008 & -0.111 & -0.163 & -0.272 & -0.103 \\
\hline R \% & -0.123 & 0.037 & -0.005 & -0.039 & -0.024 & 0.010 & -0.100 & -0.015 \\
\hline K \% & 0.232 & 0.027 & 0.127 & 0.114 & 0.149 & 0.128 & 0.165 & 0.194 \\
\hline
\end{tabular}

\section{Ratings of usefulness of anatomy learning resources}

Participants in user test 3 were asked to rank a variety of learning resources and activities including the LAHFS on their usefulness for learning anatomy from 1 (most useful) to 8 (least useful). The percentage of students ranking each resource $1^{\text {st }}$ through $7^{\text {th }}$ is shown in Figure 2 , and the mean and median ranks in Table 4. Friedman's two-way analysis of variance (ANOVA) by ranks revealed there were significant differences in rankings: $X^{2}(7)=105.578$, $\mathrm{p}<0.001$.

[Table 4.]

Table 4. Mean and median rankings of eight anatomy learning resources. ${ }^{a} \mathrm{p} \leq 0.001,{ }^{b} \mathrm{p} \leq 0.01$ compared to LAHFS.

\begin{tabular}{|l|l|}
\hline Learning resource & Mean \pm SD (median) \\
\hline Lectures, tutorials, and practicals (face-to-face sessions) & $2.1 \pm 1.6(1)^{a}$ \\
\hline Lectures, tutorials, and practicals (notes) & $2.9 \pm 1.6(3)^{a}$ \\
\hline Textbooks & $3.0 \pm 1.6(3)^{a}$ \\
\hline Haptic system (LAHFS) & $4.8 \pm 1.8(5)$ \\
\hline Atlases & $5.1 \pm 2.0(5)$ \\
\hline Software & $5.5 \pm 2.1(5)$ \\
\hline Websites & $6.2 \pm 1.9(7)^{b}$ \\
\hline Other & $7.5 \pm 1.6(8)^{a}$ \\
\hline
\end{tabular}

[Figure 2.]

Figure 2. Ranking of usefulness of eight anatomy learning resources including the haptic system. Lectures, tutorials, and practicals: face-to-face sessions (LTP F2F), and notes from these sessions (LTP notes). 


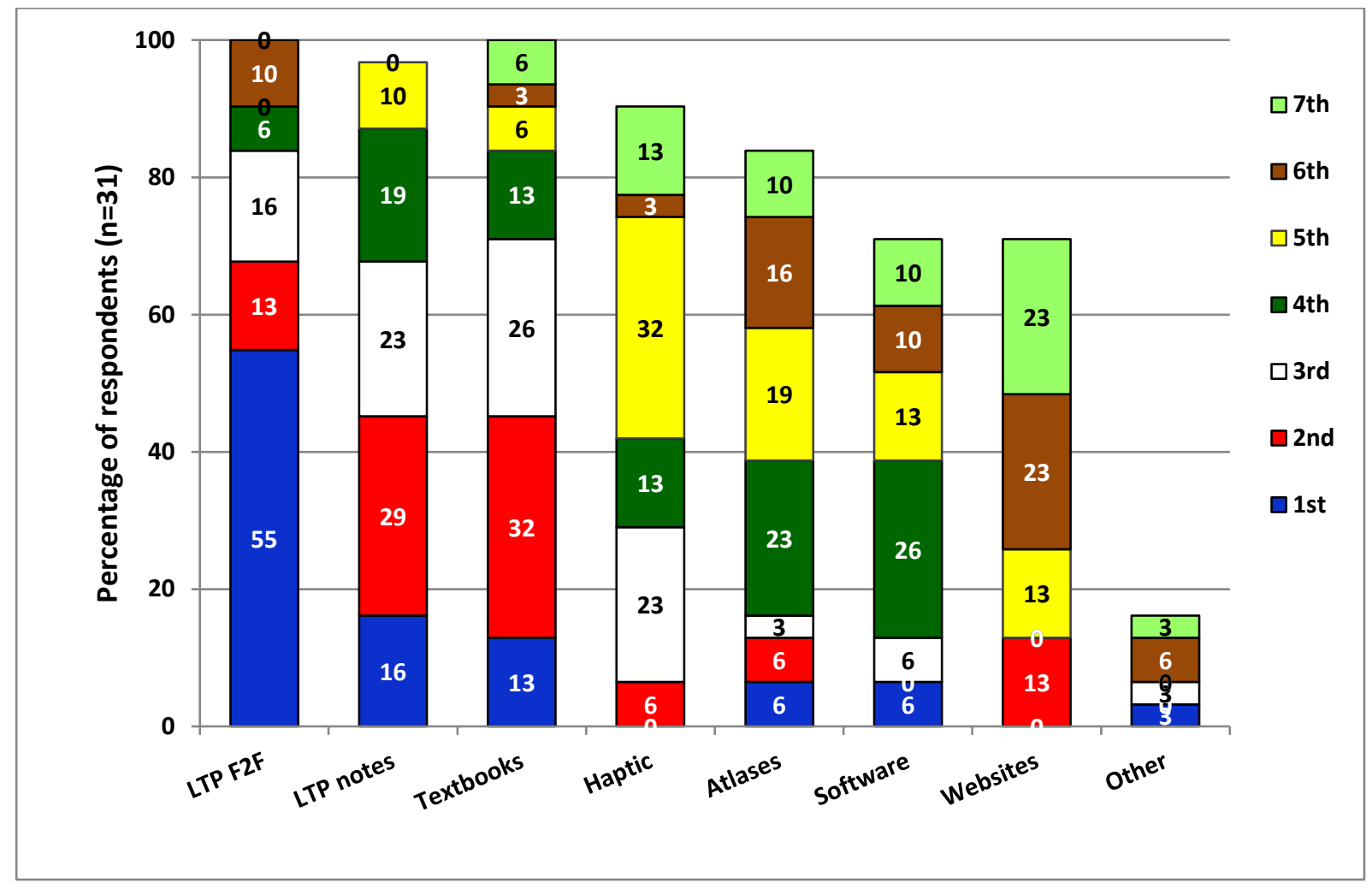

\section{Qualitative analysis of open-ended response items}

Questionnaires from user tests 1 and 2 invited participants to comment on the system. The user test 3 questionnaire asked about the best aspects of the system, those most in need of improvement along with suggestions, and what additional features could aid learning. The best aspects of the system included haptic feedback (23 comments), 3D visualisation (19), and interactivity (11). However, the haptic interface was frequently mentioned as needing improvement (29), with fewer mentions of visual aspects (4). Comments representative of identified themes are shown in Table 5.

[Table 5.]

Table 5. Representative open-response comments from participants, sorted by identified themes.

\begin{tabular}{|l|l|l|}
\hline Theme & Best Aspect & In need of improvement \\
\hline $\begin{array}{l}\text { Haptic } \\
\text { feedback / } \\
\text { interface }\end{array}$ & $\begin{array}{l}\text { The pressure that was felt when } \\
\text { pushing in. } \\
\text { You could feel the difference in } \\
\text { texture of organs. }\end{array}$ & $\begin{array}{l}\text { I found it hard to use the pen. } \\
\text { Getting used to the control of the } \\
\text { pen was hard. } \\
\text { Hard to pin point the smaller } \\
\text { structures }\end{array}$ \\
\hline 3D visualisation & $\begin{array}{l}\text { The 3D-feel of the system/sense of } \\
\text { space it gave. } \\
\text { Being able to rotate the organs }\end{array}$ & $\begin{array}{l}\text { 3D glasses } \\
\text { Improved graphics }\end{array}$ \\
\hline
\end{tabular}




\begin{tabular}{|l|l|l|}
\hline Interactivity & $\begin{array}{l}\text { Gives detail on where different } \\
\text { vessels are in regards to one } \\
\text { another. }\end{array}$ & $\begin{array}{l}\text { The ability to interact and move } \\
\text { the structures, as well as learn } \\
\text { their names. }\end{array}$ \\
\hline
\end{tabular}

\section{Discussion}

The main finding of this study was that the LAHFS was generally well-accepted by undergraduate students of human anatomy, with usefulness of the system rated higher than ease of use, and participants experienced generally low levels of stress in using the system. Students indicated that they were likely to use or recommend the system, with this intention to use correlating more strongly with perceived usefulness than ease of use (Table 2), in line with the Technology Acceptance Model in a variety of contexts (Chuttur, 2009; Legris et al., 2003), although Zacharis (2012) found perceived ease of use was a stronger predictor of intention to use than perceived usefulness for podcasts. Ease of use declined as the complexity of the system increased from versions 1 to 3 (Figure 1). Redesigning the system to progressively add anatomical complexity, for example, presenting a smaller number of major blood vessels first, checking knowledge acquisition with a quiz, and then displaying branches and tributaries of the major blood vessels, may assist learning (Burke, 2013; Young et al., 2014).

A variety of participant factors influenced user acceptance of LAHFS. Females had higher intention to use or recommend the system compared to males, despite rating their performance with the system lower. This gender difference in perceived performance is at odds with the neutrality observed by Padilla-Meléndez, del Aguila-Obra and Garrido-Moreno (2012), but accords with the findings of Ong and Lai (2006) in respect of females' lower rating of computer self-efficacy in the context of learning. Nevertheless, females rated their intention to use or recommend the system higher than males. In user test 3, MBBS students rated the usefulness of the system and quiz higher than A\&P2 students, and also performed better on the quiz. This may have been related to the close alignment of the anatomical structures depicted in the LAHFS (including from the cardiovascular, respiratory, and digestive organ systems) with the learning objectives of the laboratory practical class at which the user test was run for the MBBS students, whereas the A\&P2 students were studying a different organ system (urinary) at their laboratory practical, having studied the other systems earlier in the semester. Students with prior experience with 3D interfaces had higher intention to use or to recommend the system, and they also scored higher on the quiz. This may be due to some familiarity with the ability to rotate virtual objects on a computer or screen, as the quiz used the same interface as the learning system. This finding was in contrast to a metaanalysis which included five studies that reported no difference in anatomical knowledge outcomes for groups with different computer or 3D video history or familiarity (Yammine and Violato, 2015). Visuospatial ability was not assessed by a mental rotation test in the present study, but Yammine and Violato (2015) found that students with lower spatial ability scored lower on spatial anatomical knowledge questions.

Although there were no statistically significant correlations of VARK learning styles (recorded as percentage of $\mathrm{V}, \mathrm{A}, \mathrm{R}$, or $\mathrm{K}$ responses) with ratings of the LAHFS, there was a tendency for students with greater K preferences to rate the system higher (Table 3). 
Providing and recommending a wide variety of learning resources, to suit learners with diverse learning preferences, may help students gain a variety of perspectives, integrate information from several learning resources, and extend their own learning approaches (Azer et al., 2013; Choi-Lundberg et al., 2015). In the present study, as well as data from over 140,000 respondents on the VARK website, the kinaesthetic responses are the most frequent at $29 \%$ compared to $22-26 \%$ for V, A, and R (VARK Learn Limited, 2016). Thus, providing a CAL resource with haptic feedback may assist those with kinaesthetic preferences, particularly if they do not have frequent access to cadaveric specimens and physical anatomical models.

The LAHFS was ranked $4^{\text {th }}$ out of 8 learning activities and resources for usefulness for learning anatomy (Figure 2, Table 4). This is an impressive result for the LAHFS, given that participants used it for only once for 10-15 minutes. The rank order of other resources were similar to rankings in other studies (Choi-Lundberg et al., 2015; Azer and Eizenberg, 2007; Kerby et al., 2011; Zurada et al., 2011; Johnson et al., 2013). To achieve a middle-ranking position in such fleeting circumstances implies the LAHFS has the potential to become even more highly favoured.

Many open-response comments identified haptic feedback as the best aspect of the system, followed by 3D visualisation and interactivity. However, the haptic device was also mentioned most frequently as needing improvement. This correlated with quantitative VAS responses, with ease of use being rated lower than usefulness. Difficulty using the haptic interface may impede learning if it contributes extraneous cognitive load (van Merrienboer and Sweller, 2010). Students have reported that some technologies make their study more complicated because of the time needed to learn to use the technology (McNeill et al., 2011). Improved haptic devices, providing a more natural and intuitive interface, would improve usability of the system.

\section{Limitations of the study}

The anatomical models in the LAHFS, including their visual and haptic elements, were quite rudimentary, as they were aimed at students in the early stages of learning human anatomy. Low-fidelity simulation is appropriate in learning basic knowledge and skills (Alimisis and Zoulias, 2013). For example, a basic 'haptic cow' model adapted for first year veterinary students was well received and rated as helpful for feeling and visualising key aspects of bovine abdominopelvic anatomy (Kinnison et al., 2009). Higher fidelity data, including biomechanical properties of living tissues and testing by experienced experts, would be required for advanced anatomy learning and surgical simulation (Acosta et al., 2001).

Students self-selected to participate in the user tests, and thus may not be typical of the population of undergraduate students of human anatomy. Version 1 was tested by only 10 BComp (who were not studying anatomy) and 8 MBBS students, the latter representing only a $3.5 \%$ response rate. In contrast, versions 2 and 3 were tested by larger number of students, all of whom were studying anatomy, with response rates in the range of 20-31\%. Thus, there was likely greater self-selection bias in the first user test, which may confound the interpretation that user acceptance, especially ease of use, declined with increasing system complexity.

The VARK instrument is only one of many to measure learning styles or preferences (Coffield et al., 2004); however, it was felt to be germane to the present study, which presented information primarily through visual and touch / kinaesthetic senses. The VARK instrument has been found to have adequate validity and reliability (Leite et al., 2009).

Learning was only assessed with an immediate post-test, and was also confounded with learning from the laboratory practical content for MBBS students. A pre-test, post-test, 
delayed post-test design, at a time prior to the students studying the cardiovascular system, would better assess learning specifically from the LAHFS.

\section{Conclusions and future directions}

The LAHFS was generally well-accepted by medical and other students of human anatomy, and could serve as an additional learning resource to the suite of resources commonly used. Further development, including an improved haptic interface and addition of modules offering more realistic visual and tactile representations of anatomical structures for more advanced learners, would likely improve the pedagogical value and acceptance of the system for learners at various levels of study. Comparison of learning from LAHFS to other resources in controlled experiments, including the specific role of haptic feedback, as well as evaluation in naturalistic teaching settings, are needed to better understand its potential as a learning resource for human anatomy.

\section{Acknowledgments:}

The research was largely carried out by the first author. The second author contributed to data analysis and drafted the article based on the thesis of the first author. The last three authors are listed in alphabetical order and are subject specialists in anatomy, education and computer science, respectively.

This work was carried out in the course of candidature for a $\mathrm{PhD}$ degree, and was supported by a University of Tasmania Teaching Development Grant. The research involving human subjects was approved by the Social Science Human Research Ethics Committee (HREC) Tasmania Network (reference H0011743).

The authors thank the students who participated in this research project.

The authors declare no conflicts of interest.

\section{References:}

Acosta, E., Temkin, B., Griswold, J. A., Deeb, S. A. and Haluck, R. S. (2001), "Haptic texture generation - A heuristic method for Virtual Body Structures" Fourteenth IEEE Symposium on Computer-Based Medical Systems, Proceedings, IEEE Computer Society, pp. 395-399.

Alimisis, D. and Zoulias, E. (2013), "Aligning technology with learning theories: A simulator-based training curriculum in surgical robotics", Interactive Technology and Smart Education, Vol. 10 No. 3, pp. 211-229.

Alkhasawneh, E. (2013), "Using VARK to assess changes in learning preferences of nursing students at a public university in Jordan: implications for teaching", Nurse Education Today, Vol. 33 No. 12, pp. 1546-9.

Arevalo, C. R., Bayne, S. C., Beeley, J. A., Brayshaw, C. J., Cox, M. J., Donaldson, N. H., Elson, B. S., Grayden, S. K., Hatzipanagos, S. and Johnson, L. A. (2013), "Framework for e-learning assessment in dental education: a global model for the future", Journal of Dental Education, Vol. 77 No. 5, pp. 564-575.

Ayres, P. (2015), "State- of- the- Art Research into Multimedia Learning: A Commentary on Mayer's Handbook of Multimedia Learning", Applied Cognitive Psychology, Vol. 29 No. 4, pp. 631-636.

Azer, S. A. and Eizenberg, N. (2007), "Do we need dissection in an integrated problem-based learning medical course? Perceptions of first- and second-year students", Surgical and Radiologic Anatomy, Vol. 29 No. 2, pp. 173-180. 
Azer, S. A., Guerrero, A. P. S. and Walsh, A. (2013), "Enhancing learning approaches: Practical tips for students and teachers", Medical Teacher, Vol. 35 No. 6, pp. 433-443.

Basdogan, C., De, S., Kim, J., Muniyandi, M., Kim, H. and Srinivasan, M. (2004), "Haptics in minimally invasive surgical simulation and training", Computer Graphics and Applications, IEEE, Vol. 24 No. 2, pp. 56-64.

Bassil, Y. (2012), "A simulation model for the waterfall software development life cycle", International Journal of Engineering and Technology, Vol. 2, No.5, pp. 742-749.

Boström, L. and Hallin, K. (2012), "Learning style differences between nursing and teaching students in Sweden: A comparative study", International Journal of Higher Education, Vol. 2 No. 1, pp. 22-34

Bouwer, H. E., Valter, K. and Webb, A. L. (2016), "Current integration of dissection in medical education in Australia and New Zealand: Challenges and successes", Anatomical Sciences Education, (in press; doi: 10.1002/ase.1559)

Braun, V. and Clarke, V. (2006), "Using thematic analysis in psychology", Qualitative Research in Psychology, Vol. 3 No. 2, pp. 77-101.

Burke, P. F. (2013), "Seeking simplicity in complexity: The relative value of ease of use (EOU)- based product differentiation", Journal of Product Innovation Management, Vol. 30 No. 6, pp. 1227-1241.

Burns, M. (2013), "Success, failure or no significant difference: Charting a course for successful educational technology integration", International Journal of Emerging Technologies in Learning, Vol. 8 No. 1, pp. 38-45.

Choi-Lundberg, D. L., Low, T. F., Patman, P., Turner, P. and Sinha, S. N. (2015), "Medical student preferences for self-directed study resources in gross anatomy", Anatomical Sciences Education, (in press; doi: 10.1002/ase.1549).

Choi-Lundberg, D. L., Cuellar, W. A. \& Williams, A. M. M. (2016), "Online dissection audio-visual resources for human anatomy: Undergraduate medical students' usage and learning outcomes" Anatomical Sciences Education, in press, accepted 12 February 2016.

Chuttur, M. (2009), "Overview of the Technology Acceptance Model: Origins, developments and future directions", Sprouts: Working papers on Information Systems, Vol. 9 No. 37, pp. 64-84

Clark, R. C. and Mayer, R. E. (2003), e-Learning and the Science of Instruction: Proven Guidelines for Consumers and Designers of Multimedia Learning, Pfeiffer, San Francisco, CA.

Codd, A. M. and Choudhury, B. (2011), "Virtual reality anatomy: Is it comparable with traditional methods in the teaching of human forearm musculoskeletal anatomy?", Anatomical Sciences Education, Vol. 4 No. 3, pp. 119-125.

Coffield, F., Moseley, D., Hall, E. and Ecclestone, K. 2004. Learning styles and pedagogy in post-16 learning: A systematic and critical review, Learning and Skills Research Centre, London, UK.

Cornwall, J. and Pollard, M. F. (2012), "Evaluation of free i-applications for tertiary level gross anatomy education", Australasian Medical Journal, Vol. 5 No. 4, pp. 239-242.

Craig, S., Tait, N., Boers, D. and Mcandrew, D. (2010), "Review of anatomy education in Australian and New Zealand medical schools", ANZ Journal of Surgery, Vol. 80 No. 4, pp. 212-216.

Davis, A. M., Bersoff, E. H. and Comer, E. R. (1988), "A strategy for comparing alternative software development life cycle models", IEEE Transactions on Software Engineering, Vol. 14 No. 10, pp. 1453-1461. 
Dev, P., Montgomery, K., Senger, S., Heinrichs, W. L., Srivastava, S. and Waldron, K. (2002), "Simulated medical learning environments on the internet", Journal of the American Medical Informatics Association, Vol. 9 No. 5, pp. 437-447.

Drake, R. L., Mcbride, J. M., Lachman, N. and Pawlina, W. (2009), "Medical education in the anatomical sciences: The winds of change continue to blow", Anatomical Sciences Education, Vol.2 No. 6, pp. 253-259.

Edmunds, J. M., Kendall, P. C., Ringle, V. A., Read, K. L., Brodman, D. M., Pimentel, S. S. and Beidas, R. S. (2013), "An examination of behavioral rehearsal during consultation as a predictor of training outcomes", Administration and Policy in Mental Health and Mental Health Services Research, Vol. 40 No. 6, pp. 456-466.

Esteban, G., Fernández, C., Conde, M. Á. and García-Peñalvo, F. J. (2014), "Playing with SHULE: surgical haptic learning environment", Proceedings of the Second International Conference on Technological Ecosystems for Enhancing Multiculturality, ACM, 247-253.

Fang, T.-Y., Wang, P.-C., Liu, C.-H., Su, M.-C. and Yeh, S.-C. (2014), "Evaluation of a haptics-based virtual reality temporal bone simulator for anatomy and surgery training", Computer Methods and Programs in Biomedicine, Vol. 113 No. 2, pp. 674681.

Fitzgerald, J. E., White, M. J., Tang, S. W., Maxwell-Armstrong, C. A. and James, D. K. (2008), "Are we teaching sufficient anatomy at medical school? The opinions of newly qualified doctors", Clinical Anatomy, Vol. 21 No. 7, pp. 718-724.

Fleming, N. D. (1995), I'm different; not dumb. Modes of presentation (VARK) in the tertiary classroom. Research and Development in Higher Education, Proceedings of the 1995 Annual Conference of the Higher Education and Research Development Society of Australasia (HERDSA), Vol. 18, pp. 308-313.

Gaglani, S. M. and Topol, E. J. (2014), "iMedEd: The role of mobile health technologies in medical education", Academic Medicine, Vol. 89 No. 9, pp. 1207-1209.

Granger, N. A. (2004), "Dissection laboratory is vital to medical gross anatomy education", The Anatomical Record Part B: The New Anatomist, Vol. 281B No. 1, pp. 6-8.

Hoffman, H. and Vu, D. (1997), "Virtual reality: teaching tool of the twenty-first century?", Academic Medicine, Vol. 72 No. 12, pp. 1076-81.

Howell, J. N., Conatser, R. R., Williams, R. L., Burns, J. M. and Eland, D. C. (2008), "The virtual haptic back: a simulation for training in palpatory diagnosis", BMC Medical Education, Vol. 8 No. 14, DOI: 10.1186/1472-6920-8-14.

Ingole, A., Kumar, D. S. A., Bahattere, V. and Chaware, S. (2015), "Application of Multimedia Design Principle in Learning Anatomy and Physiology", Indian Journal of Anatomy, Vol. 4 No. 1, pp. 17-20.

Itkowitz, B., Handley, J. and Zhu, W. (2005), "The OpenHaptics ${ }^{\mathrm{TM}}$ toolkit: a library for adding 3D Touch ${ }^{\mathrm{TM}}$ navigation and haptics to graphics applications", Proceedings of the First Joint Eurohaptics Conference and Symposium on Haptic Interfaces for Virtual Environment and Teleoperator Systems. IEEE Computer Society, pp. 590-591.

Johnson, I. P., Palmer, E., Burton, J. and Brockhouse, M. (2013), "Online learning resources in anatomy: What do students think?", Clinical Anatomy, Vol. 26 No. 5, pp. 556-563.

Jonas, G. A. and Norman, C. S. (2011), "Textbook Websites: User Technology Acceptance Behaviour", Behaviour \& Information Technology, Vol. 30 No. 2, pp. 147-159.

Kerby, J., Shukur, Z. N. and Shalhoub, J. (2011), "The Relationships Between Learning Outcomes and Methods of Teaching Anatomy as Perceived by Medical Students", Clinical Anatomy, Vol. 24 No. 4, pp. 489-497. 
Khot, Z., Quinlan, K., Norman, G. R. and Wainman, B. (2013), "The relative effectiveness of computer-based and traditional resources for education in anatomy", Anatomical Sciences Education, Vol. 6 No. 4, pp. 211-215.

Kim, R. H., Gilbert, T., Ristig, K. and Chu, Q. D. (2013), "Surgical resident learning styles: faculty and resident accuracy at identification of preferences and impact on ABSITE scores", Journal of Surgical Research, Vol. 184 No. 1, pp. 31-36.

Kinnison, T., Forrest, N. D., Frean, S. P. and Baillie, S. (2009), "Teaching bovine abdominal anatomy: Use of a haptic simulator", Anatomical Sciences Education, Vol. 2 No. 6, pp. 280-285.

Legris, P., Ingham, J. and Collerette, P. (2003), "Why do people use information technology? A critical review of the technology acceptance model", Information \& Management, Vol. 40 No. 3, pp. 191-204.

Leite, W. L., Svinicki, M. and Shi, Y. (2009), "Attempted Validation of the Scores of the VARK: Learning Styles Inventory With Multitrait-Multimethod Confirmatory Factor Analysis Models", Educational and Psychological Measurement, Vol. 70 No. 2, pp. 323-339.

Lewis, T. L., Burnett, B., Tunstall, R. G. and Abrahams, P. H. (2014), "Complementing anatomy education using three-dimensional anatomy mobile software applications on tablet computers", Clinical Anatomy, Vol. 27 No. 3, pp. 313-320.

Lim, K. H. A., Loo, Z. Y., Goldie, S. J., Adams, J. W. and Mcmenamin, P. G. (2015), "Use of 3D printed models in medical education: A randomized control trial comparing 3D prints versus cadaveric materials for learning external cardiac anatomy", Anatomical Sciences Education, doi: 10.1002/ase.1573

Lingard, L. and Kennedy, T. J. (2010), Qualitative research methods in medical education. In: Swanwick, T. (ed.) Understanding Medical Education: Evidence, Theory and Practice. 1st ed. Wiley-Blackwell, Chichester, West Sussex, UK.

Marangunić, N. and Granić, A. (2015), "Technology acceptance model: a literature review from 1986 to 2013", Universal Access in the Information Society, Vol. 14 No. 1, pp. 81-95.

Mclachlan, J. C., Bligh, J., Bradley, P. and Searle, J. (2004), "Teaching anatomy without cadavers", Medical Education, Vol. 38 No. 4, pp. 418-424.

Mclachlan, J. C. and Patten, D. (2006), "Anatomy teaching: ghosts of the past, present and future", Medical Education, Vol. 40 No. 3, pp. 243-253.

Mcneill, M., Ming Diao, M. and Gosper, M. (2011), "Student uses of technology in learning: two lenses", Interactive Technology and Smart Education, Vol. 8 No. 1, pp. 5-17.

Ong, C.-S. and Lai, J.-Y. (2006), "Gender differences in perceptions and relationships among dominants of e-learning acceptance", Computers in Human Behavior, Vol. 22 No. 5, pp. 816-829.

Padilla-Meléndez, A., Del Aguila-Obra, A. R. and Garrido-Moreno, A. (2013), "Perceived playfulness, gender differences and technology acceptance model in a blended learning scenario", Computers \& Education, Vol. 63, pp. 306-317.

Panait, L., Akkary, E., Bell, R. L., Roberts, K. E., Dudrick, S. J. and Duffy, A. J. (2009), "The role of haptic feedback in laparoscopic simulation training", Journal of Surgical Research, Vol. 156 No. 2, pp. 312-316.

Plomp, T. (2009), "Educational design research: An introduction", In Plomp, T and Nieveen, N.(Eds), An introduction to Educational Design Research, pp. 9-35.

Preece, D., Williams, S. B., Lam, R. and Weller, R. (2013), "'Let's Get Physical": Advantages of a physical model over 3D computer models and textbooks in learning imaging anatomy", Anatomical Sciences Education, Vol. 6 No. 4, pp. 216-224. 
Rengier, F., Mehndiratta, A., Von Tengg-Kobligk, H., Zechmann, C. M., Unterhinninghofen, R., Kauczor, H.-U. and Giesel, F. L. (2010), "3D printing based on imaging data: review of medical applications", International Journal of Computer Assisted Radiology and Surgery, Vol. 5 No. 4, pp. 335-341.

Rohrer, D. and Pashler, H. (2012), "Learning styles: where's the evidence?", Medical Education, Vol. 46 No. 7, pp. 634-635.

Royce, W. W. (1970), "Managing the development of large software systems" Proceedings of IEEE Western Electronic Show and Convention, in Los Angeles, 328-388.

Ruthenbeck, G. S. and Reynolds, K. J. (2015), "Virtual reality for medical training: the stateof-the-art", Journal of Simulation, Vol. 9 No. 1, pp. 16-26.

Sakellariou, S., Ward, B. M., Charissis, V., Chanock, D. and Anderson, P. (2009), "Design and implementation of augmented reality environment for complex anatomy training: inguinal canal case study", Proceedings of the 3rd International Conference on Virtual and Mixed Reality: Held as Part of HCI International 2009Springer-Verlag, pp. 605614.

Saltarelli, A. J., Roseth, C. J. and Saltarelli, W. A. (2014), "Human cadavers vs. multimedia simulation: A study of student learning in anatomy", Anatomical Sciences Education, Vol. 7 No. 5, pp. 331-339.

Schvartzman, S., Salisbury, K., Silva, R. and Girod, S. (2014), "Surgical Simulation and Education", International Journal of Computer Assisted Radiology and Surgery, Vol. 9 No. 1, pp. S123-S138.

Shams, L. and Seitz, A. R. (2008), "Benefits of multisensory learning", Trends in Cognitive Sciences, Vol. 12 No. 11, pp. 411-417.

Sugand, K., Abrahams, P. and Khurana, A. (2010), "The Anatomy of Anatomy: A Review for Its Modernization", Anatomical Sciences Education, Vol.3 No. 2, pp. 83-93.

Temkin, B., Acosta, E., Malvankar, A. and Vaidyanath, S. (2006), "An interactive threedimensional virtual body structures system for anatomical training over the Internet", Clinical Anatomy, Vol. 19 No. 3, pp. 267-274.

Thomas, M. P. (2013), "The role of simulation in the development of technical competence during surgical training: a literature review", International Journal of Medical Education, Vol. 4, pp. 48-58.

Ullrich, S. and Kuhlen, T. (2012), "Haptic palpation for medical simulation in virtual environments", IEEE Transactions on Visualization and Computer Graphics, Vol. 18 No. 4, pp. 617-625.

Van Merrienboer, J. J. G. and Sweller, J. (2010), "Cognitive load theory in health professional education: Design principles and strategies", Medical Education, Vol. 44 No. 1, pp. 85-93.

Vark Learn Limited. (2016), "VARK: A guide to learning styles, and research \& statistics", available at: http://vark-learn.com/ and http://vark-learn.com/introduction-tovark/research-statistics/ (Accessed 6/1/2016).

Weber, J., Hincke, M., Patasi, B., Jalali, A. and Wiper-Bergeron, N. (2012), "The Virtual Anatomy Lab: an eDemonstrator pedagogical agent can simulate student-faculty interaction and promote student engagement", Medical Education Development, Vol. 2 No. 1, pp. 5.

Wu, F., Chen, X., Lin, Y., Wang, C., Wang, X., Shen, G., Qin, J. and Heng, P. A. (2014), "A virtual training system for maxillofacial surgery using advanced haptic feedback and immersive workbench", The International Journal of Medical Robotics and Computer Assisted Surgery, Vol. 10 No. 1, pp. 78-87. 
Yammine, K. and Violato, C. (2015), "A meta-analysis of the educational effectiveness of three-dimensional visualization technologies in teaching anatomy", Anatomical Sciences Education, Vol. 8 No. 6, pp. 525-538.

Yeom, S. (2011), "Augmented reality for learning anatomy" Australasian Society for Computers in Learning in Tertiary Education in Hobart, Tasmania, pp. 1377- 1383.

Yeom, S., Choi-Lundberg, D., Fluck, A. and Sale, A. (2013), "User acceptance of a haptic interface for learning anatomy" International Association for Development of the Information Society (IADIS) Multi Conference on Computer Science and Information Systems: e-Learning in Prague, Czech Republic.

Young, J. Q., Van Merrienboer, J., Durning, S. and Ten Cate, O. (2014), "Cognitive load theory: Implications for medical education: AMEE guide no. 86", Medical Teacher, Vol. 36 No. 5, pp. 371-384.

Zacharis, N. Z. (2012), "Predicting college students' acceptance of podcasting as a learning tool", Interactive Technology and Smart Education, Vol. 9 No. 3, pp. 171-183.

Zurada, A., St Gielecki, J., Osman, N., Tubbs, R. S., Loukas, M., Zurada-Zielinska, A., Bedi, N. and Nowak, D. (2011), "The study techniques of Asian, American, and European medical students during gross anatomy and neuroanatomy courses in Poland", Surgical and Radiologic Anatomy, Vol. 33 No. 2, pp. 161-169. 